TITLE:

\title{
Theoretical study on first-principles dielectric properties of silicate compounds
}

AUTHOR(S):

Nakamura, K; Doi, K; Fujitani, K; Tachibana, A

\section{CITATION:}

Nakamura, K ... [et al]. Theoretical study on first-principles dielectric properties of silicate compounds. PHYSICAL REVIEW B 2005, 71(4):

045332.

ISSUE DATE:

2005-01

URL:

http://hdl.handle.net/2433/39869

RIGHT:

Copyright 2005 American Physical Society 
PHYSICAL REVIEW B 71, 045332 (2005)

\title{
Theoretical study on first-principles dielectric properties of silicate compounds
}

\author{
Koichi Nakamura, Kentaro Doi, Kiwamu Fujitani, and Akitomo Tachibana* \\ Department of Engineering Physics and Mechanics, Kyoto University, Kyoto 606-8501, Japan \\ (Received 26 April 2004; revised manuscript received 14 September 2004; published 26 January 2005)
}

\begin{abstract}
We have devised some cluster models of silicon dioxide and silicate oxides, and have discussed the microscopic structures and electronic properties in these high- $\kappa$ cluster models by carrying out $a b$ initio electronicstate calculations. Dielectric constants for our models have been calculated by means of polarizability. We have confirmed that the dielectric constants increase rapidly as the ratio of zirconium or hafnium is raised for $\mathrm{SiO}_{2}$-rich silicate oxides. The driving force of the stability in electronic processes can be visualized in terms of the quantum mechanical energy densities based on the regional density functional theory, and alternative images of microscopic electronic stresses have been given.
\end{abstract}

DOI: 10.1103/PhysRevB.71.045332

PACS number(s): 77.22.-d, 77.84.Bw, 61.43.Dq, 31.15.Ew

\section{INTRODUCTION}

Recent improvement of electronics has been supported by rapid progress of ultralarge scale integration (ULSI) technology. In particular, complementary metal-oxide-semiconductor field effect transistors (MOSFET's) play an important role in ULSI, and many studies of the complementary metal oxide semiconductor (CMOS) gate insulator have been performed in both academic and industrial fields of material research. So far, the CMOS gate insulator has been assigned to silicon dioxide $\left(\mathrm{SiO}_{2}\right)$ thin film for a long time. However, many serious problems about leak current and reliability for the $\mathrm{SiO}_{2}$ thin-film gate insulator spring up as the thickness of $\mathrm{SiO}_{2}$ thin film is reduced in order to raise the performance of FET. ${ }^{1}$ It means that the thickness of $\mathrm{SiO}_{2}$ film will reach the physical limit of minimum in future, and practically $\mathrm{SiO}_{2}$ film thinner than approximately $1.5 \mathrm{~nm}$ cannot be used as the CMOS gate insulator. ${ }^{1}$ Therefore, the development of newgeneration MOSFET's by the novel gate insulator which overcomes the problems in the $\mathrm{SiO}_{2}$ thin film is urgently necessary. One of the main trends in researches in the gate insulator is fabrication and characterization of thin film using materials with high dielectric constants, called high- $\kappa$ materials. Many high- $\kappa$ materials such as tantalum pentoxide $\left(\mathrm{Ta}_{2} \mathrm{O}_{5}\right)$, strontium titanate $\left(\mathrm{SrTiO}_{3}\right)$, alumina $\left(\mathrm{Al}_{2} \mathrm{O}_{3}\right)$, yttrium oxide $\left(\mathrm{Y}_{2} \mathrm{O}_{3}\right)$, promethium oxide $\left(\mathrm{Pr}_{2} \mathrm{O}_{3}\right)$, titanium dioxide $\left(\mathrm{TiO}_{2}\right)$, zirconium dioxide $\left(\mathrm{ZrO}_{2}\right)$, hafnium dioxide $\left(\mathrm{HfO}_{2}\right)$, etc., ${ }^{2}$ have been studied for the application to the gate insulator with reduced leakage, improved resistance to boron diffusion, and better reliability characteristics. However, most of them are not thermally and chemically stable in direct contact with Si. At present, some high- $\kappa$ materials are known to be thermally and chemically stable on $\mathrm{Si}$ : cerium dioxide $\left(\mathrm{CeO}_{2}\right),{ }^{3} \mathrm{Pr}_{2} \mathrm{O}_{3},{ }^{4} \mathrm{Al}_{2} \mathrm{O}_{3},{ }^{5}$ and $\mathrm{Zr}$ and $\mathrm{Hf}$ silicates. ${ }^{2,6-8}$

$\mathrm{Zr}$ and $\mathrm{Hf}$ silicates $\left(\mathrm{Zr}_{x} \mathrm{Si}_{1-x} \mathrm{O}_{2}, \mathrm{Hf}_{x} \mathrm{Si}_{1-x} \mathrm{O}_{2}\right)$ are hopeful materials for the CMOS gate insulators because of their thermal and chemical stability on $\mathrm{Si}$ as mentioned above, to say nothing of high dielectric constant. The thin film of these silicates is usually formed as an interfacial layer between $\mathrm{SiO}_{2}$ and the metal oxide when $\mathrm{ZrO}_{2}$ or $\mathrm{HfO}_{2}$ is deposited on $\mathrm{Si}$ substrate. The properties of the interfacial layer are important in determining the characteristics of CMOS, but these properties have not yet been clear. In order to control the characteristics of gate insulator by these silicates, it is essential to clarify the dependence of structure and properties on $\mathrm{Zr}$ or Hf concentration. For the silicates with small amount of $\mathrm{Zr}$ or $\mathrm{Hf}$ (3-8 at. \%), called $\mathrm{SiO}_{2}$-rich silicates, they are deposited on $\mathrm{Si}$ with chemical stability as much as $\mathrm{SiO}_{2}$, and therefore, the structures of silicate/ $\mathrm{Si}$ interface are thought to be similar to the structure of $\mathrm{SiO}_{2} / \mathrm{Si}$ interface. On the other hand, the dielectric constant of $\mathrm{SiO}_{2}$-rich $\mathrm{Zr}$ and $\mathrm{Hf}$ silicates shows strange behavior; the dielectric constants of $\mathrm{Zr}$ silicates with $3-8$ at. \% $\mathrm{Zr}[\kappa=8-11$ (Refs. 6-8)] are much larger than the estimated values by a linear extrapolation of dielectric constants between $\mathrm{SiO}_{2}[\kappa=3.9$ (Ref. 2)] and $\mathrm{ZrSiO}_{4}[\kappa=12.6$ (Ref. 2) $]$ as shown in Fig. $1,{ }^{9}$ and similarly, those of $\mathrm{Hf}$ silicates with small amount of $\mathrm{Hf}(\kappa=\sim 10)$ are much larger than the estimated values by a linear extrapolation of $\mathrm{SiO}_{2}$ and $\mathrm{HfSiO}_{4}[\kappa=13-20$ (Ref. 2)]. The gap between the experimental value and the estimated value by a

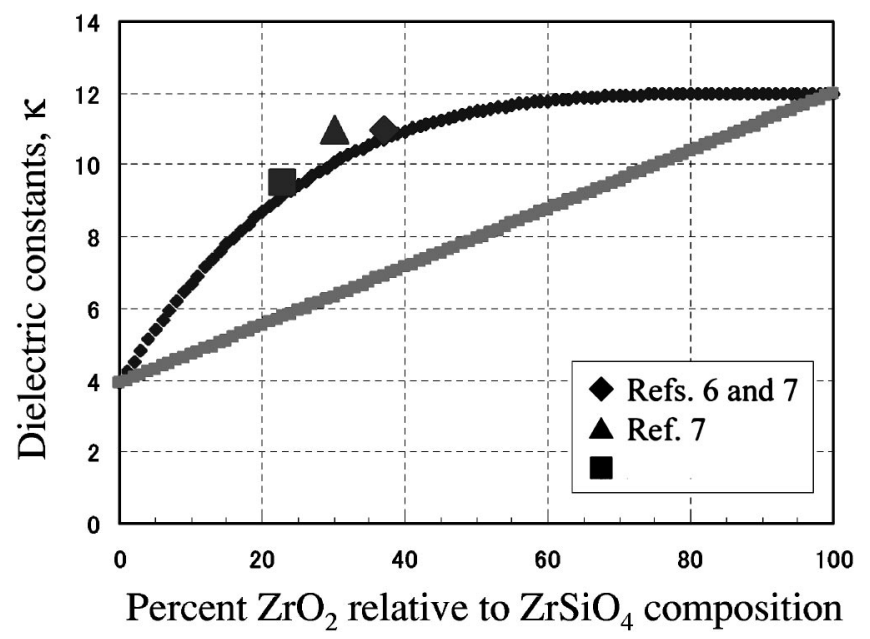

FIG. 1. Dielectric constant of $\mathrm{SiO}_{2}$-rich silicate compounds. The curve indicates the dielectric constant calculated from Ref. 9 as a function of the percent $\mathrm{Zr}(\mathrm{Hf}) \mathrm{O}_{2}$ relative to the stoichiometric silicate compound composition, $\mathrm{Zr}(\mathrm{Hf}) \mathrm{SiO}_{4}$. Experimental points are from Refs. 6-8. The linear line denotes a linear extrapolation between the dielectric constant of $\mathrm{SiO}_{2}$ and nominal dielectric constant of 12 for $\mathrm{Zr}(\mathrm{Hf}) \mathrm{SiO}_{4}$. 


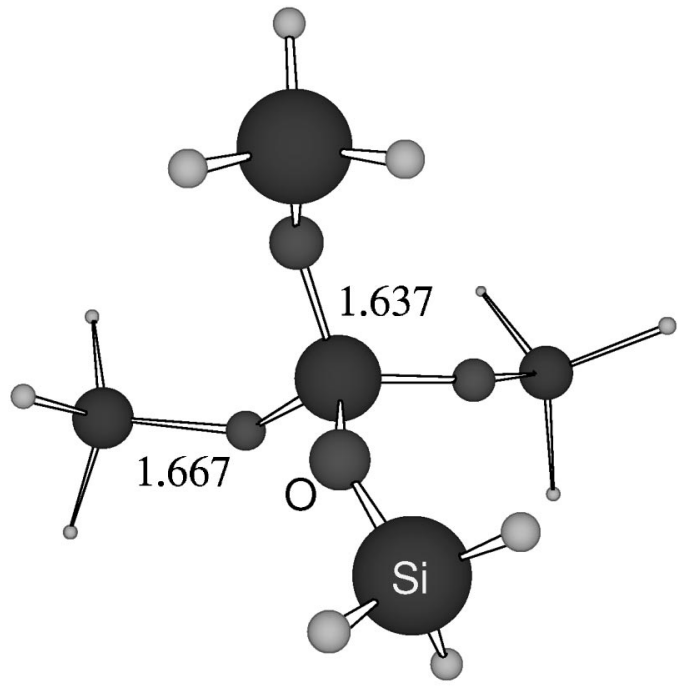

1

FIG. 2. B3LYP optimized structure of the $\mathrm{SiO}_{2}$ cluster model 1 . All bond lengths are in angstroms. $\angle \mathrm{Si}-\mathrm{O}-\mathrm{Si}$ is equal to $139.6^{\circ}$.

linear extrapolation is considered to be due to the change of local structure in the vicinity of $\mathrm{Zr}$ or $\mathrm{Hf}$ according to the $\mathrm{Zr}$ or Hf concentration. ${ }^{9}$ In this paper, we shall present some cluster models of $\mathrm{SiO}_{2}$ and $\mathrm{SiO}_{2}$-rich silicates and discuss the microscopic structure and electronic properties for these models by carrying out ab initio electronic-state calculations.

\section{COMPUTATIONAL METHOD}

$\mathrm{Zr}$ and Hf silicates are known to be amorphous materials and these detailed structures have not been clarified experimentally yet. In this study, we have devised some cluster models for amorphous silicates, because these cluster models are better to characterize the amorphous structure than periodic models. Here, we have devised two types of silicate models referred to Lucovsky and Rayner. ${ }^{9}$ One has the structure where each $\mathrm{O}$ atom of four siloxy groups is coordinated to $\mathrm{Zr}$ or $\mathrm{Hf}$, called the fourfold-coordinated model, and the other has the structure where six $\mathrm{O}$ atoms in two siloxy groups and two siladioxy groups are arranged around $\mathrm{Zr}$ or $\mathrm{Hf}$, called the sixfold-coordinated model. Lucovsky and Rayner ${ }^{9}$ gave an account of local structure of $\mathrm{Zr}_{x} \mathrm{Si}_{1-x} \mathrm{O}_{2}$ and $\mathrm{Hf}_{x} \mathrm{Si}_{1-x} \mathrm{O}_{2}$ silicates; they have the fourfold-coordinated structure in $x \sim 0.1$ and the sixfold-coordinated structure in $x \sim 0.25-0.3$. In this paper, we treated small cluster models 1-5 as local structures of $\mathrm{SiO}_{2}$ crystal and the amorphous structures of silicates. Figure 2 shows the model of $\mathrm{SiO}_{2}$ crystal $1\left(\mathrm{Si}_{5} \mathrm{O}_{4} \mathrm{H}_{12}\right)$, where the structure is based on the fourfold-coordinate structure, similarly as actual structures of $\alpha$-quartz, $\alpha$-cristobalite, etc., and the edge Si atoms are terminated by hydrogen atoms. Figure 3 displays the models of $\mathrm{Zr}$ and $\mathrm{Hf}$ silicates in the fourfold-coordinate structure 2 $\left(\mathrm{ZrSi}_{4} \mathrm{O}_{4} \mathrm{H}_{12}\right)$ and $3\left(\mathrm{HfSi}_{4} \mathrm{O}_{4} \mathrm{H}_{12}\right)$, and the models of silicates in the sixfold-coordinate structure $4\left(\mathrm{ZrSi}_{4} \mathrm{O}_{6} \mathrm{H}_{10}\right)$ and $5\left(\mathrm{HfSi}_{4} \mathrm{O}_{6} \mathrm{H}_{10}\right)$ are shown in Fig. 4.

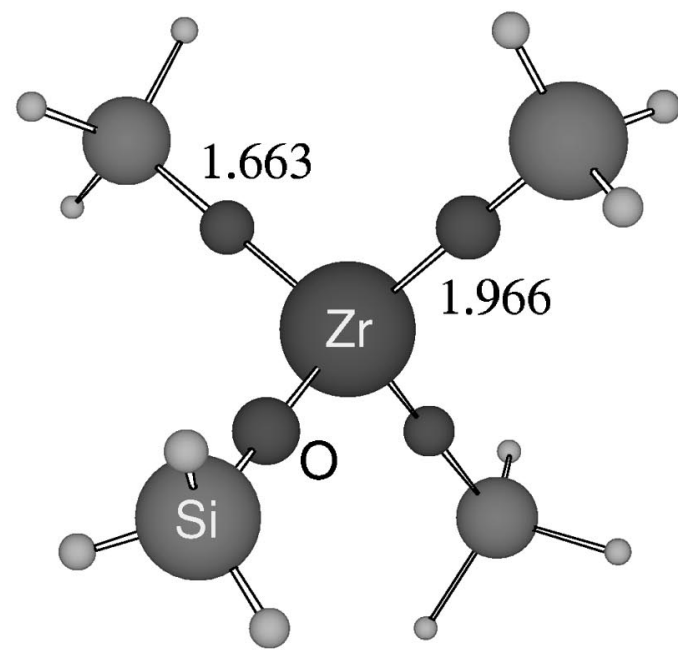

2

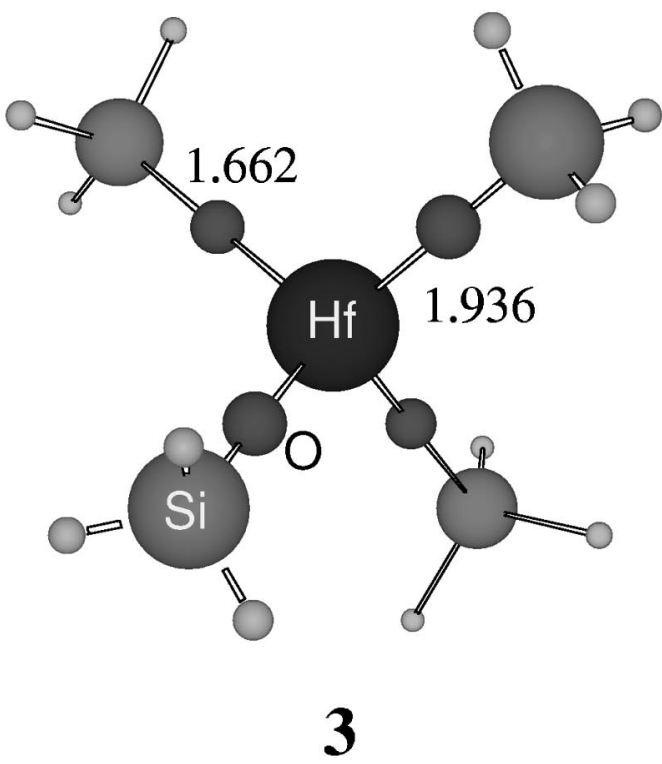

FIG. 3. B3LYP optimized structure of the fourfold-coordinated silicate models 2 and 3 . All bond lengths are in angstroms. $\angle \mathrm{Zr}$ $\mathrm{O}-\mathrm{Si}$ and $\angle \mathrm{Zr}-\mathrm{O}-\mathrm{Si}$ are respectively equal to $180.0^{\circ}$.

We optimized each of these models by ab initio quantum chemical calculation. We used the restricted Hartree-Fock (RHF) method ${ }^{10}$ and the density-functional method by the Lee-Yang-Parr gradient-corrected correlation functional ${ }^{11}$ with Becke's three hybrid parameters ${ }^{12}$ (B3LYP), and employed the improved LanL2DZ basis set, which consists of the Dunning-Huzinaga (DH) double-zeta basis set ${ }^{13}$ (D95) for $\mathrm{H}$ and $\mathrm{O}$ atoms, where $d$-type $\mathrm{DH}$ polarization function was added on $\mathrm{O}$ atoms, and the double-zeta basis set with the effective core potential (ECP) by Hay and Wadt ${ }^{14-16}$ for $\mathrm{Si}, \mathrm{Zr}$, and $\mathrm{Hf}$ atoms, where $d$-type (for $\mathrm{Si}$ ) and $p$-type (for $\mathrm{Zr}$ and $\mathrm{Hf}$ ) Huzinaga polarization functions ${ }^{17}$ were appended. Furthermore, we introduced large cluster models of $\mathrm{SiO}_{2}$ crystal model $6\left(\mathrm{Si}_{18} \mathrm{O}_{18} \mathrm{H}_{36}\right)$ and $\mathrm{SiO}_{2}$-rich silicates in the fourfold-coordinated structure $7\left(\mathrm{ZrSi}_{17} \mathrm{O}_{18} \mathrm{H}_{36}\right)$ and 8 

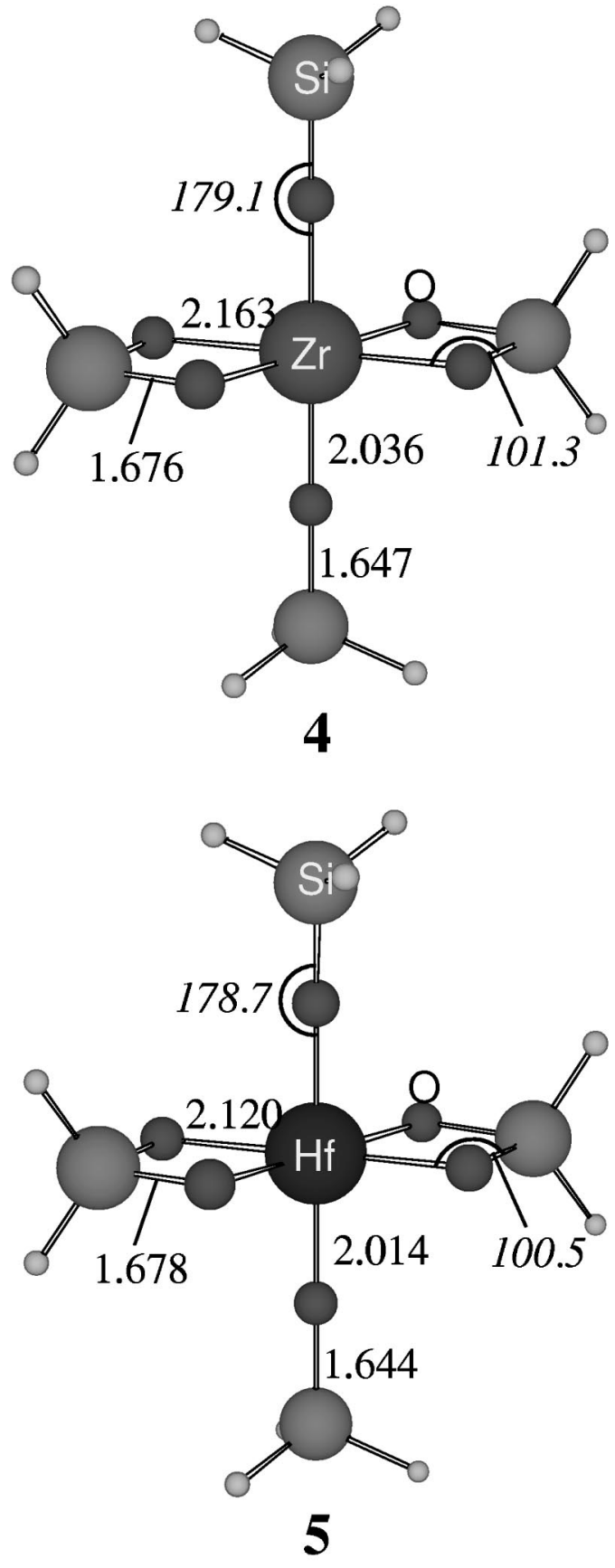

FIG. 4. B3LYP optimized structure of the sixfold-coordinated silicate models 4 and 5 . All bond lengths are in å angstroms and all angles are in degrees.

$\left(\mathrm{HfSi}_{17} \mathrm{O}_{18} \mathrm{H}_{36}\right.$ ). Cluster models $1-8$ were set up without any net charge. A $b$ initio calculations were performed by the molecular regional (MR) density functional theory (DFT) program. ${ }^{18}$

\section{RESULTS AND DISCUSSION}

The B3LYP optimized geometrical parameters of models $1-5$ are given in Figs. 2-4. Without the polarization function on $\mathrm{O}$ atoms, the point-group symmetry of model 1 is $T_{d}$ where $\angle \mathrm{Si}-\mathrm{O}-\mathrm{Si}$ is $180^{\circ}$. It turns into $S_{4}$, where $\angle \mathrm{Si}-\mathrm{O}-\mathrm{Si}$ changes from $180^{\circ}$ to $139.6^{\circ}$, by adding the $d$-type polarization function on $\mathrm{O}$ atoms, and then, optimized Si-O lengths and $\mathrm{Si}-\mathrm{O}-\mathrm{Si}$ angles are agreement with the experimental data of $\mathrm{SiO}_{2}$ crystals; $\angle \mathrm{Si}-\mathrm{O}-\mathrm{Si}$ is $147^{\circ}$ in $\alpha$-cristobalite and $144^{\circ}$ in $\alpha$-quartz. ${ }^{19}$ This result ensures that our methods of calculation have validity for accuracy, and it is proved that polarization on $\mathrm{O}$ atoms is necessary to discuss the microscopic structure. On the contrary, the point-group symmetry of fourfold-coordinated silicate models 2 and 3 is $T_{d}$, where both $\angle \mathrm{Zr}-\mathrm{O}-\mathrm{Si}$ in model 2 and $\angle \mathrm{Hf}-\mathrm{O}-\mathrm{Si}$ in model 3 are $180.0^{\circ}$. Therefore, microscopic structures in the vicinity of $\mathrm{Zr}$ and $\mathrm{Hf}$ are radically different from that around $\mathrm{Si}$ atom in $\mathrm{SiO}_{2}$ even when $\mathrm{Zr}$ or $\mathrm{Hf}$ concentration is quite small. In the six-coordinated silicate models 4 and 5, Zr-O and $\mathrm{Hf}-\mathrm{O}$ bond lengths are longer by $0.07-0.2 \AA$ than those in the corresponding fourfold-coordinated models. Structures of $\mathrm{Zr}-\mathrm{O}$ -Si and Hf-O-Si parts for the siladioxy groups are not colinear because both $\mathrm{O}$ atoms are coordinated to $\mathrm{Zr}$ or $\mathrm{Hf}$ atom in each siladioxy group, but $\angle \mathrm{Zr}-\mathrm{O}-\mathrm{Si}$ and $\angle \mathrm{Hf}-\mathrm{O}$-Si for the siloxy groups are almost equal to $180^{\circ}$ similarly as those of the fourfold-coordinated models.

The electronic interaction in each model has been demonstrated in terms of the quantum energy density ${ }^{20-24}$ based on the regional functional theory. ${ }^{20-25}$ The electronic kinetic energy density $n_{T}(\vec{r})$ is defined as follows:

$$
\begin{aligned}
n_{T}(\vec{r})= & \frac{1}{2} \sum_{i} \nu_{i}\left(\left\{-\frac{\hbar^{2}}{2 m} \Delta \psi_{i}^{*}(\vec{r})\right\} \psi_{i}(\vec{r})+\psi_{i}^{*}(\vec{r})\right. \\
& \left.\times\left\{-\frac{\hbar^{2}}{2 m} \Delta \psi_{i}(\vec{r})\right\}\right),
\end{aligned}
$$

where $m$ is the mass of electron, $\psi_{i}(\vec{r})$ is the natural orbital, and $\nu_{i}$ is the occupation number of $\psi_{i}(\vec{r})$, respectively. The $n_{T}(\vec{r})$ divides the space into the electronic drop region $R_{D}\left[n_{T}(\vec{r})>0\right]$, where valence electrons can move freely as in the meaning of classical mechanics, and the electronic atmosphere region $R_{A}\left[n_{T}(\vec{r})<0\right]$, where electrons can move only with the quantum mechanical tunneling effect. The total electronic force density $\vec{F}^{S}(\vec{r})$ is represented as

$$
\vec{F}^{S}(\vec{r})=\vec{\tau}^{S}(\vec{r})+\vec{X}^{S}(\vec{r}),
$$

where $\vec{\tau}^{S}(\vec{r})$ and $\vec{X}^{S}(\vec{r})$ denotes the electronic tension density and the electronic external force density, respectively. The superscript $S$ means that these densities originate in the velocity density operator $\hat{S}(\vec{r}){ }^{20-24} \vec{\tau}^{S}(\vec{r})$ has quantum mechanical origin, and is defined as $\vec{\tau}^{S}(\vec{r})={ }^{t}\left(\tau^{S 1}(\vec{r}), \tau^{S 2}(\vec{r}), \tau^{S 3}(\vec{r})\right)$ with

$$
\begin{aligned}
\tau^{S k}(\vec{r})= & \frac{\hbar^{2}}{4 m} \sum_{i} \nu_{i}\left(\psi_{i}^{*}(\vec{r}) \frac{\partial \Delta \psi_{i}(\vec{r})}{\partial x^{k}}-\frac{\partial \psi_{i}^{*}(\vec{r})}{\partial x^{k}} \Delta \psi_{i}(\vec{r})\right. \\
& \left.+\frac{\partial \Delta \psi_{i}^{*}(\vec{r})}{\partial x^{k}} \psi_{i}(\vec{r})-\Delta \psi_{i}^{*}(\vec{r}) \frac{\partial \psi_{i}(\vec{r})}{\partial x^{k}}\right)
\end{aligned}
$$

for $k=1,2$, and 3 . In the stationary state, the $\vec{\tau}^{S}(\vec{r})$ exactly cancels $\vec{X}^{S}(\vec{r}),{ }^{20-24}$ and balances with the electric field $\vec{E}(\vec{r})$ exerted on electron because $\vec{X}^{S}(\vec{r})$ is equivalent to $\vec{E}(\vec{r}) . n_{T}(\vec{r})$ 


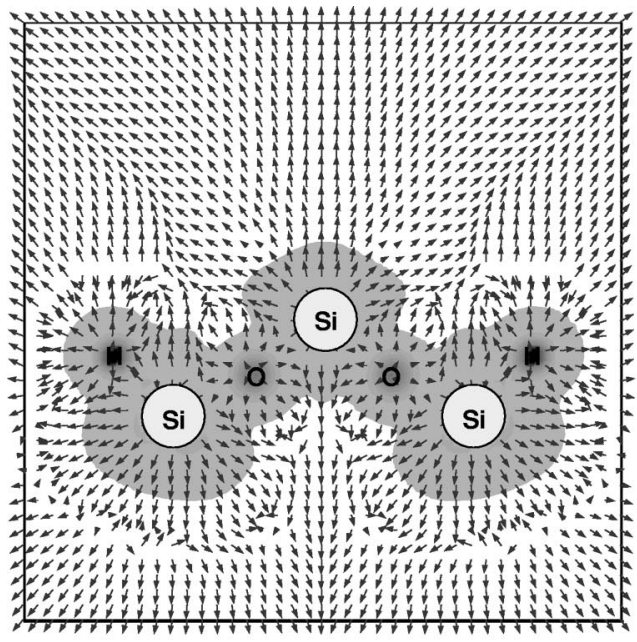

(a)

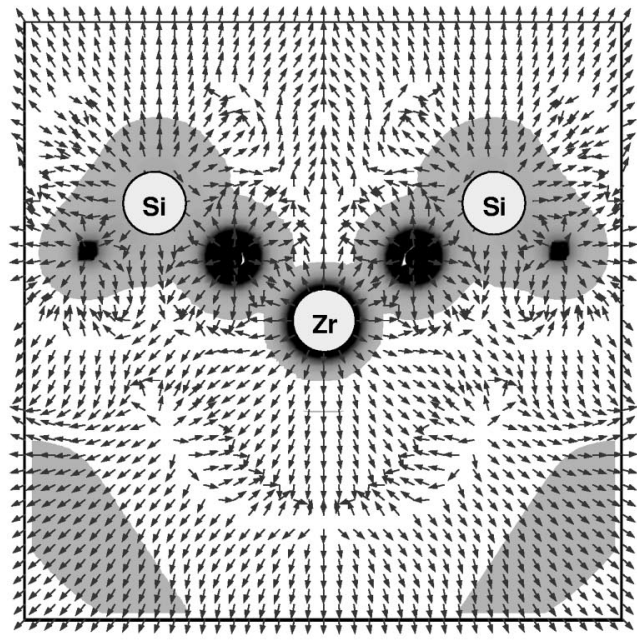

(b)

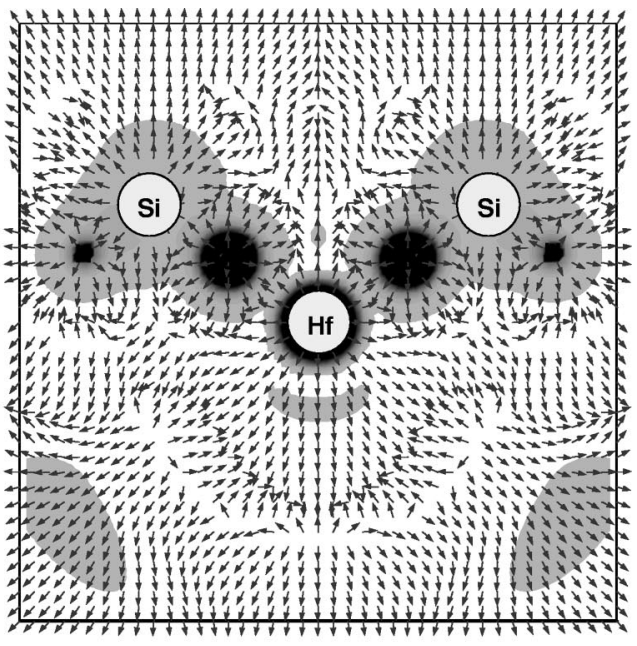

(c)

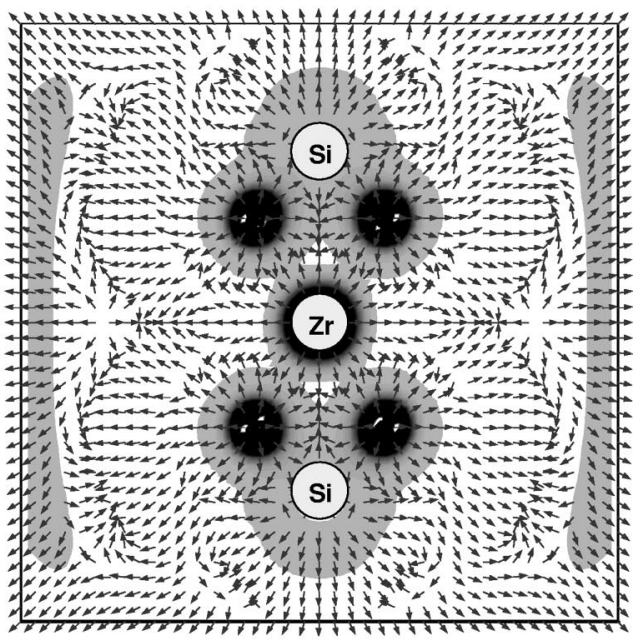

(d)

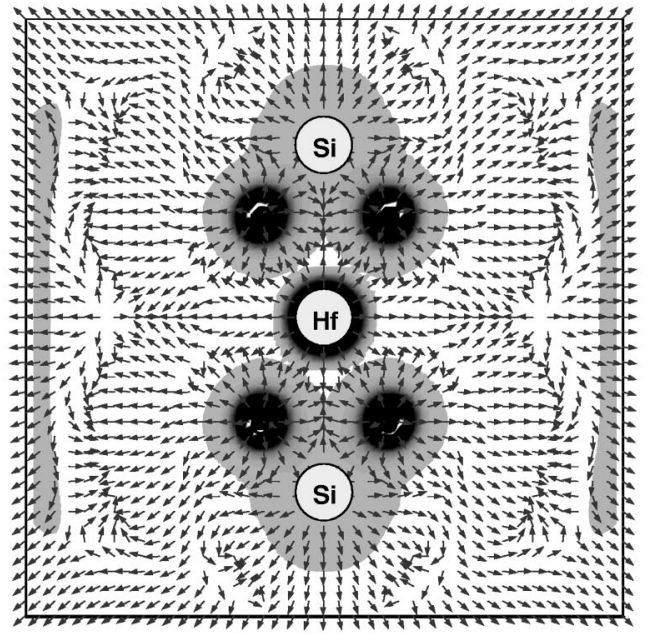

(e)

FIG. 5. The electronic kinetic energy densities (background) and the electronic tension densities (arrows) in cluster models 1-5: (a) cross section of model 1 containing three Si atoms, (b) that of model 2 containing $\mathrm{Zr}$ atom and two Si atoms, (c) that of model 3 containing $\mathrm{Hf}$ atom and two Si atoms, (d) that of model 4 containing $\mathrm{Zr}$ atom and two $\mathrm{Si}$ atoms in siladioxy groups, and (e) that of model 4 containing Hf atom and two $\mathrm{Si}$ atoms in siladioxy groups. Circles on atoms represent a cross section of ECP with the plane of map. 
TABLE I. Polarizabilities, shape volumes, and dielectric constants of models 1-5. $\alpha$ means an average of three eigenvalues of polarizability tensor.

\begin{tabular}{cccc}
\hline \hline Model & $\begin{array}{c}\text { Polarizability } \\
\alpha\left(\mathrm{C}^{2} \mathrm{~m}^{2} \mathrm{~J}^{-1}\right)\end{array}$ & $\begin{array}{c}\text { Shape volume } \\
V\left(\AA^{3}\right)\end{array}$ & $\begin{array}{c}\text { Dielectric constant } \\
\text { RHF }\end{array}$ \\
& & & \\
1 & $1.58 \times 10^{-39}$ & 98.53 & 5.14 \\
2 & $1.93 \times 10^{-39}$ & 95.11 & 8.57 \\
3 & $1.87 \times 10^{-39}$ & 94.39 & 7.87 \\
4 & $4.37 \times 10^{-39}$ & 97.53 & - \\
5 & $4.29 \times 10^{-39}$ & 96.47 & - \\
B3LYP & & & 7.29 \\
1 & $1.78 \times 10^{-39}$ & 98.91 & 40.19 \\
2 & $2.32 \times 10^{-39}$ & 94.13 & 26.22 \\
3 & $2.22 \times 10^{-39}$ & 93.55 & - \\
4 & $4.04 \times 10^{-39}$ & 96.18 & - \\
5 & $4.02 \times 10^{-39}$ & 94.98 & \\
\hline \hline
\end{tabular}

and $\vec{\tau}^{S}(\vec{r})$ of each model can be calculated originally by use of MR DFT program ${ }^{18}$ as shown in Fig. 5. They have disclosed the driving force of the stability and given new images of microscopic electronic stresses.

Electronic dielectric constants of each model were calculated by means of the Clausius-Mossotti (CM) equation. This equation is given by ${ }^{26}$

$$
\varepsilon=\left(1+\frac{8 \pi \alpha}{12 V \pi \varepsilon_{0}}\right) /\left(1-\frac{4 \pi \alpha}{12 V \pi \varepsilon_{0}}\right)
$$

where $\alpha$ is the polarizability, $\varepsilon_{0}$ is the dielectric constant of vacuum, and $V$ is the volume. However, it is difficult to apply the CM equation to a cluster model because the value of volume cannot be determined uniquely though this equation is sensitive with respect to the volume. In this paper, the $\mathrm{CM}$ equation shall be applied to the cluster models by using polarizability of them derived by the computation in terms of the coupled-perturbed Hartree-Fock (CPHF) algorithm ${ }^{27}$ and the intrinsic shape ${ }^{20}$ of cluster models and the volume, called the shape volume; the volume of atoms surrounded by the outermost interface $S$ for $R_{D}$ of valence electrons. Table I lists polarizabilities $\alpha$, shape volumes $V$, and dielectric constants $\varepsilon$ calculated by $\mathrm{CM}$ equation for the RHF and the B3LYP wave functions. For the sixfold-coordinated silicate models 4 and 5, polarizability is too large to derive dielectric constant because the denominator of Eq. (4) gives a negative value. The dielectric constant of each of models 1-3 for the B3LYP wave function is larger than that of the corresponding one for the RHF wave function because the B3LYP method gives larger polarizability as compared with the RHF method. In particular it is found that a contamination of $\mathrm{Zr}$ or $\mathrm{Hf}$ gives rise to a rapid increase in the dielectric constants for the B3LYP wave function. From these results, it is important for the derivation of polarizability to make consideration the effect of electron correlation.
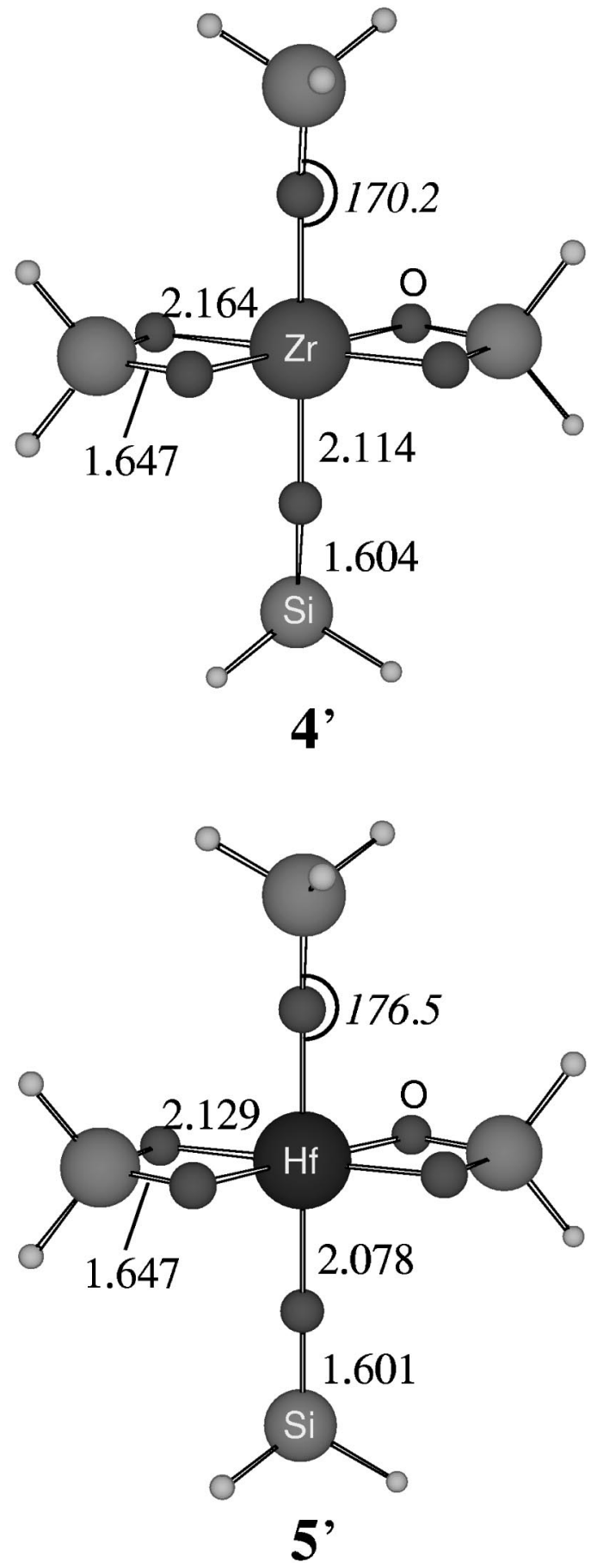

FIG. 6. B3LYP optimized structure of the negative-charged sixfold-coordinated silicate models 4 and 5 . All bond lengths are in angstroms and all angles are in degrees.

For the sixfold-coordinated silicate models, we considered different charged state under the assumption that $\mathrm{Zr}-\mathrm{O}$ and $\mathrm{Hf}-\mathrm{O}$ interactions are complete ionic bonds. If all ligands, two siloxy ligands and two siladioxy ligands, are negative with closed-shells, the siloxy ligands and the siladioxy ligands should be represented as $\mathrm{SiH}_{3} \mathrm{O}^{-}$and ${ }^{-} \mathrm{OSiH}_{2} \mathrm{O}^{-}$, respectively, that is, ligands to metal have -6 charges totally. $\mathrm{Zr}$ and $\mathrm{Hf}$ atoms can have positive charges of up to +4 , so that we treated here the sixfold-coordinated 
TABLE II. B3LYP polarizabilities, shape volumes, and dielectric constants of negative-charged models $4^{\prime}$ and $5^{\prime} . \alpha$ means an average of three eigenvalues of polarizability tensor.

\begin{tabular}{cccc}
\hline \hline Model & $\begin{array}{c}\text { Polarizability } \\
\alpha\left(\mathrm{C}^{2} \mathrm{~m}^{2} \mathrm{~J}^{-1}\right)\end{array}$ & $\begin{array}{c}\text { Shape volume } \\
V\left(\AA^{3}\right)\end{array}$ & $\begin{array}{c}\text { Dielectric constant } \\
\varepsilon\end{array}$ \\
\hline $4^{\prime}$ & $2.68 \times 10^{-39}$ & 105.66 & 62.62 \\
$5^{\prime}$ & $2.58 \times 10^{-39}$ & 103.07 & 49.77 \\
\hline \hline
\end{tabular}

silicate models with negative charge of -2 , denoted $4^{\prime}$ $\left(\mathrm{ZrSi}_{4} \mathrm{O}_{6} \mathrm{H}_{10}^{2-}\right)$ and $5^{\prime}\left(\mathrm{HfSi}_{4} \mathrm{O}_{6} \mathrm{H}_{10}^{-2}\right)$. In order to calculate the dianionic species, it is frequently requested that diffuse functions should be added to basis sets. We employed the Dunning-Hay diffuse function ${ }^{13}$ for $\mathrm{O}$ atoms in the calculations of $4^{\prime}$ and $5^{\prime}$. The B3LYP optimized structures of them are displayed in Fig. 6, and Table II shows polarizabilities, shape volumes, and dielectric constants for the B3LYP wave functions. Polarizabilities of negative state are smaller than those of neutral state in models 4 and 5, and then dielectric constants can be given by Eq. (4). Thus, it is hard to simulate the dielectric property for the system where several charged states can be selected.

In order to inspect the quantity of dielectric constants, we have expanded a series of calculations into large cluster models. Figure 7 shows the B3LYP optimized structure of model 6 . This model has $C_{i}$ symmetry, and it is composed of a 12 -membered ring in $\alpha$-cristobalite $\mathrm{SiO}_{2}$ crystal, where six $\mathrm{Si}$ atoms and six $\mathrm{O}$ atoms stand in a circle alternately, and 12 terminal siloxy groups without any dangling bonds. Local structures around each $\mathrm{Si}$ atom on the 12-membered ring correspond to the structure of model 1. The B3LYP opti- mized structure is presented in closely the geometry for microscopic structure of $\alpha$-cristobalite $\mathrm{SiO}_{2}$ crystal; the $\mathrm{Si}-\mathrm{O}$ bond lengths are 1.638-1.640 $\AA$ in the 12-membered ring, $1.630-1.633 \AA$ for the axial Si-O bonds, $1.634-1.636 \AA$ for the equatorial $\mathrm{Si}-\mathrm{O}$ bonds, and $1.665-1.668 \AA$ for the terminal $\mathrm{Si}-\mathrm{O}$ bonds in the siloxy groups, and all $\angle \mathrm{Si}-\mathrm{O}-\mathrm{Si}$ are with in the range of $140-144^{\circ}$.

Furthermore, we devised large cluster models of $\mathrm{SiO}_{2}$-rich silicate in the fourfold-coordinated structure 7 and 8 by replacing a part of optimized structure of model 6 with the silicate part as shown in Fig. 8, that is, atoms marked with an asterisk in Fig. 7 were removed where other atoms were fixed, and then $\mathrm{O}-\mathrm{Zr}\left(\mathrm{OSiH}_{3}\right)_{2}-\mathrm{O}$ or $\mathrm{O}-\mathrm{Hf}\left(\mathrm{OSiH}_{3}\right)_{2}-\mathrm{O}$ unit was set up with holding each bond length of the unit on the optimized one in the small cluster modal 2 or 3 and keeping $\angle \mathrm{Zr}$-O-Si or $\angle \mathrm{Hf}-\mathrm{O}-\mathrm{Si}$ to $180^{\circ}$ under the condition that movement of the edge $\mathrm{O}$ atoms in the unit from the original position in model 6 is minimized.

We simulated dielectric constants of the large clusters in the same procedure as mentioned above for small clusters. Polarizabilities, shape volumes, and dielectric constants of large models for the B3LYP wave functions are tabulated in Table III. The simulated dielectric constant of modal 6 is a little smaller than that of model 1 , but these values can be regarded as the same quantities. Our simulated values are quantitatively larger to experimental value, because it is considered that the shape volumes are underestimated as the volume applied to the $\mathrm{CM}$ equation, and terminal $\mathrm{H}$ atoms in the cluster would affect the polarizability and shape volume particularly in the small clusters. However, qualitative reliability for dielectric property can be emphasized through the simulations for large models, which give the results that the

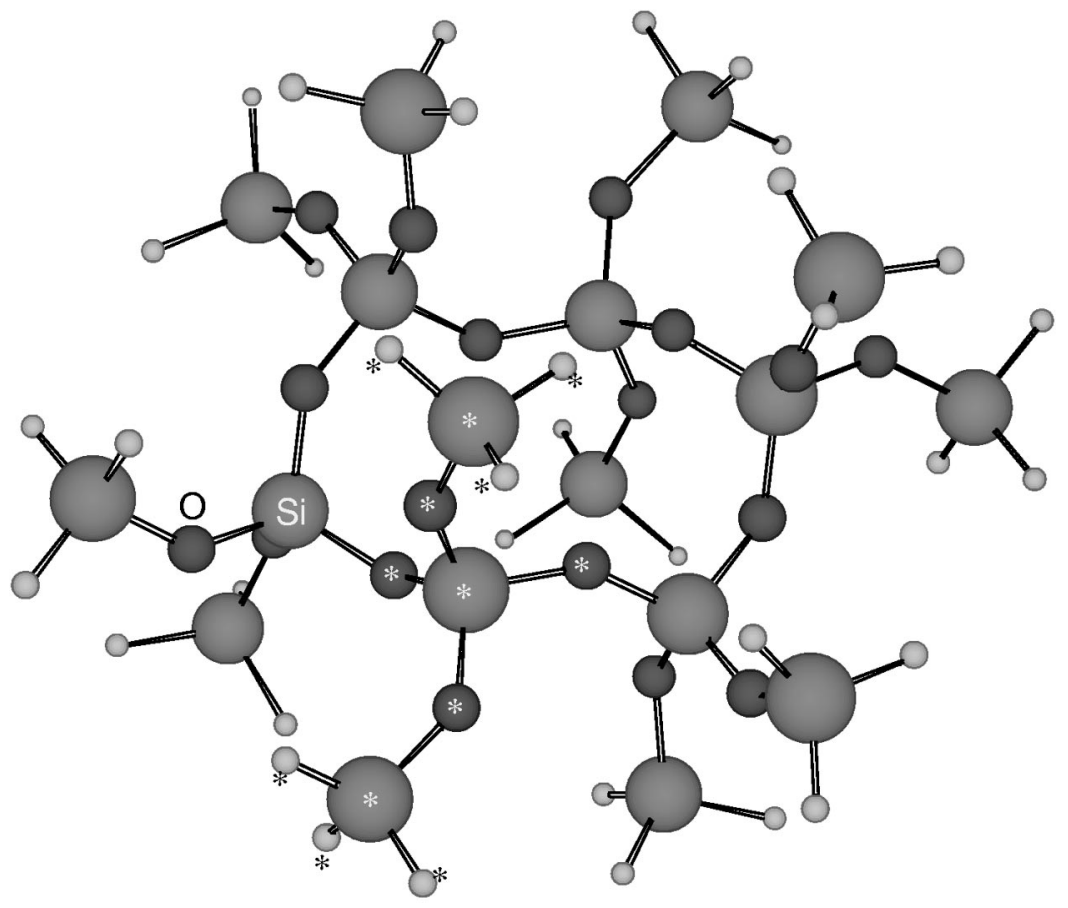

FIG. 7. B3LYP optimized structure of the large cluster models of $\mathrm{SiO}_{2}$ crystal 6. Bond lengths and angles are noted in the text. The asterisk marks denote atoms removed for introducing the large silicate models 7 and 8 . 

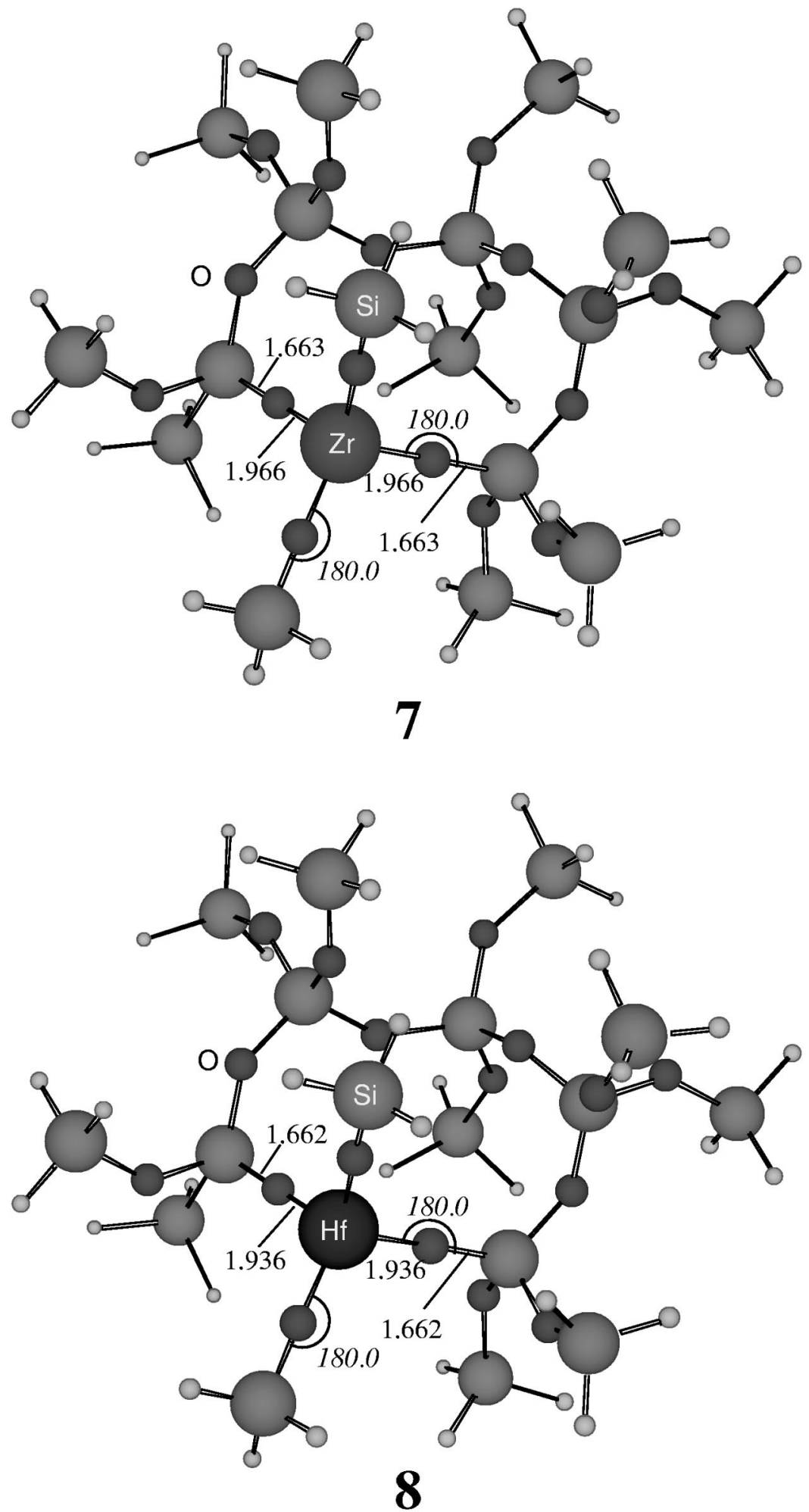

FIG. 8. The large cluster models of $\mathrm{SiO}_{2}$-rich silicate 7 and 8 . All bond lengths are in angstroms and all angles are in degrees. contamination of $\mathrm{Zr}$ or $\mathrm{Hf}$ atom raises the polarizability and dielectric constant.

\section{CONCLUSION}

We have carried out $a b$ initio electronic-state calculations to discuss the microscopic structures and dielectric properties of $\mathrm{SiO}_{2}, \mathrm{Zr}$ silicate $\left(\mathrm{Zr}_{x} \mathrm{Si}_{1-x} \mathrm{O}_{2}\right)$, and $\mathrm{Hf}$ silicate
$\left(\mathrm{Hf}_{x} \mathrm{Si}_{1-x} \mathrm{O}_{2}\right)$. We have devised two types of silicate model, the fourfold-coordinated model for $x \sim 0.1$ and the sixfoldcoordinated model for $x \sim 0.25-0.3$. The microscopic structure of $\mathrm{SiO}_{2}$ can be represented as the fourfold-coordinated model 1 and optimized geometrical parameters are agreement with the experimental values by using the $d$-type polarization function on $\mathrm{O}$ atoms. The silicate models of the fourfold-coordinated structure 2 (for $\mathrm{Zr}$ ) and 3 (for $\mathrm{Hf}$ ) have 
TABLE III. B3LYP polarizabilities, shape volumes, and dielectric constants of large models 6-8. $\alpha$ means an average of three eigenvalues of polarizability tensor.

\begin{tabular}{lccc}
\hline \hline & Polarizability & Shape volume & Dielectric constant \\
\hline Model & $\alpha\left(\mathrm{C}^{2} \mathrm{~m}^{2} \mathrm{~J}^{-1}\right)$ & $V\left(\AA^{3}\right)$ & $\varepsilon$ \\
\hline 6 & $6.01 \times 10^{-39}$ & 339.75 & 6.97 \\
7 & $8.56 \times 10^{-39}$ & 337.20 & 65.80 \\
8 & $8.45 \times 10^{-39}$ & 336.14 & 54.27 \\
\hline \hline
\end{tabular}

different local structures in the vicinity of $\mathrm{Zr}$ and $\mathrm{Hf}$ atoms from $\mathrm{SiO}_{2}$ even in a low metal concentration. The dielectric constants simulated by means of the CM equation with polarizability in terms of the CPHF algorithm ${ }^{27}$ and shape volume in terms of the regional density functional theory ${ }^{20-25}$ are raised remarkably by the contamination of $\mathrm{Zr}$ or $\mathrm{Hf}$ atom, in particular dominantly by the B3LYP method. From these results, it is important for the derivation of polarizability to make consideration the effect of electron correlation. Furthermore, we have adopted new large cluster models representing $\mathrm{SiO}_{2}$ crystal and $\mathrm{SiO}_{2}$-rich silicates. For the large $\mathrm{SiO}_{2}$ model 6, local structures correspond to the structure of model 1, and optimized structure is presented in closely the geometry for microscopic structure of $\alpha$-cristobalite $\mathrm{SiO}_{2}$ crystal. The dielectric constant of model 6 is a little smaller than that of model 1 , so it may be said that the calculated dielectric constant approaches the experimental value as the cluster size gets larger. The contamination of $\mathrm{Zr}$ or $\mathrm{Hf}$ atom is raised dielectric constants abruptly in the large cluster models 7 and 8 . The quantum energy densities ${ }^{20-24}$ based on the regional functional theor ${ }^{20-25}$ have disclosed the driving force of the stability and given alternative images of microscopic electronic stresses.

\section{ACKOWLEDGMENTS}

This research is conducted as a program for the "Promotion of Leading Researches" in Special Coordination Funds for Promoting Science and Technology by Ministry of Education, Culture, Science and Technology, Japan. This paper is also supported in part by Center of Excellence for Research and Education on "Complex Functional Mechanical System" as a COE program of the Ministry of Education, Culture, Science and Technology, Japan. We express our gratitude for their support.

\footnotetext{
*Author to whom correspondence should be addressed. Email address: akitomo@kues.kyoto-u.ac.jp

${ }^{1}$ J. H. Stathis and D. J. Dimaria, Tech. Dig. - Int. Electron Devices Meet. 1998, 167.

${ }^{2}$ G. D. Wilk, R. M. Wallace, and L. M. Anthony, J. Appl. Phys. 89, 5243 (2001).

${ }^{3}$ M. Yoshimoto, T. Maeda, T. Ohnishi, G. H. Lee, and H. Loinuma, Mater. Res. Soc. Symp. Proc. 41, 210 (1996).

${ }^{4}$ J. P. Liu, P. Zaumseil, E. Bugiel, and H. J. Osten, Appl. Phys. Lett. 79, 671 (2000).

${ }^{5}$ E. P. Gusev, M. Copel, E. Cartier, I. J. R. Baumvol, C. Krig, and M. A. Gribelyuk, Appl. Phys. Lett. 76, 176 (2000).

${ }^{6}$ G. D. Wilk and R. M. Wallace, Appl. Phys. Lett. 74, 2854 (1999).

${ }^{7}$ G. D. Wilk and R. M. Wallace, J. Appl. Phys. 87, 484 (2000).

${ }^{8}$ G. D. Wilk and R. M. Wallace, Appl. Phys. Lett. 76, 112 (2000).

${ }^{9}$ G. Lucovsky and G. B. Rayner, Appl. Phys. Lett. 77, 2912 (2000).

${ }^{10}$ C. C. J. Roothaan, Rev. Mod. Phys. 23, 69 (1951).

${ }^{11}$ A. D. Becke, J. Chem. Phys. 98, 5648 (1993).

${ }^{12}$ C. Lee, W. Yang, and R. G. Parr, Phys. Rev. B 37, 785 (1988).

${ }^{13}$ T. H. Dunning, Jr., and P. J. Hay, in Modern Theoretical Chemistry, edited by H. F. Schaefer III (Plenum, New York, 1976).

${ }^{14}$ P. J. Hay and W. R. Wadt, J. Chem. Phys. 82, 270 (1985).

${ }^{15}$ W. R. Wadt and P. J. Hay, J. Chem. Phys. 82, 284 (1985).
}

${ }^{16}$ P. J. Hay and W. R. Wadt, J. Chem. Phys. 82, 295 (1985).

${ }^{17}$ Gaussian Basis Sets for Molecular Calculations, edited by S. Huzinaga (Elsevier, New York, 1984), pp. 23 and 24.

${ }^{18}$ K. Nakamura, K. Doi, and A. Tachibana, Molecular Regional DFT program package, ver. 1, Tachibana Lab., Kyoto University, Kyoto, 2004.

${ }^{19}$ R. W. G. Wyckoff, Crystal Structures, 2nd ed. (Interscience Publishers, New York, 1963), Vol. I, pp. 243-246;316-319.

${ }^{20}$ A. Tachibana, J. Chem. Phys. 115, 3497 (2001).

${ }^{21}$ A. Tachibana, in Stress Incuded Phenomena in Metallization, edited by S. P. Baker (American Institute of Physics, New York, 2002), pp. 105-116.

${ }^{22}$ A. Tachibana, in Reviews in Modern Quantum Chemistry: A Celebration of the Contribution of Robert Parr, edited by K. D. Sen (World Scientific, Singapore, 2002), Chap. 45, pp. 1327-1366.

${ }^{23}$ A. Tachibana, in Fundamental Worlds of Quantum Chemistry: A Tribute to the Memory of Per-Olov Löwdin, edited by E. Brändas and E. Kryachko (Kluwer Academic Publishers, Dordrecht, 2003), Vol. 2, pp. 211-239.

${ }^{24}$ A. Tachibana, Int. J. Quantum Chem. 100, 981 (2004).

${ }^{25}$ A. Tachibana, Theor. Chem. Acc. 102, 188 (1999).

${ }^{26} \mathrm{P}$. W. Atkins and J. de Paula, Physical Chemistry, 7th ed. (Oxford University Press, Oxford, 2002), p. 693.

${ }^{27}$ S. P. Karna and M. Dupuis, J. Comput. Chem. 12, 487 (1991). 